\title{
Steering drift and wheel movement during braking: static and dynamic measurements
}

J Klaps $^{1}$ and A J Day ${ }^{2 *}$

${ }^{1}$ Ford Motor Company, Ford-Werke Aktiengesellschaft, Fabriekente Genk, Genk, Belgium

${ }^{2}$ University of Bradford, School of Engineering, Design and Technology, Bradford, UK

The manuscript was received on 4 June 2003 and was accepted after revision for publication on 27 July 2004.

DOI: $10.1243 / 095440705 X 5975$

\begin{abstract}
This paper reports on an experimental investigation into braking-related steering drift in motor vehicles, and follows on from a previous paper by the authors in which it was concluded that braking can cause changes in wheel alignment that in turn affect the toe-steer characteristics of each wheel and therefore the straight-line stability of the vehicle during braking. Changes in suspension geometry during braking, their magnitude and the relationships between the braking forces and the suspension geometry and compliance are further investigated in an experimental study of wheel movement arising from compliance in the front suspension and the steering system of a passenger car during braking. Using a kinematic and compliance $(\mathrm{K} \& \mathrm{C})$ test rig, movement of the front wheels and the suspension subframe, together with corresponding changes in suspension and steering geometry under simulated braking conditions, have been measured and compared with dynamic measurements of the centre points of the front wheels. The results have enabled the causes and effects of steering drift during braking to be better understood in the design of front suspension systems for vehicle stability during braking.
\end{abstract}

Keywords: automotive, braking, steering drift, suspension, design, experiment

\section{INTRODUCTION}

Steering drift during braking occurs when the driver must apply a corrective steering torque in order to maintain course. By modern standards of vehicle handling and performance, even minor deviation of a vehicle from a straight line while braking is unacceptable [1]. The braking forces at the wheels of a vehicle are reacted through the suspension components at the subframe or chassis system [2], and because these are generally not symmetrical from side to side (particularly at the front of the vehicle), and the suspension, subframe and chassis systems are compliantly mounted, equal braking forces and torques on each side can cause different deflections at each wheel. The kinematic effect of this can be to create dynamic changes in wheel alignment and steering geometry during braking, and on the

* Corresponding author: School of Engineering, Design and Technology, University of Bradford, Bradford, BD7 1DP, UK. email: a.j.day@bradford.ac.uk front wheels, where braking loads are highest, such changes have been shown to be a major contributory factor to steering drift during braking [1].

Compliance steer in the suspension system, which results from the application of lateral or longitudinal forces at the tyre contact patch, is considered to be one of the biggest contributors to straight-line stability during braking [3]. Compliance steer is affected by (among others) the design of rubber components in suspensions. The present authors [1] used vehicle tests to investigate four parameters associated with steering geometry, viz. toe steer, camber, caster and scrub radius that affected steering drift, and found that compliance in the bushes of the lower wishbone rear bush of the front suspension of the particular vehicle studied had a significant effect on toe steer and hence steering drift during braking.

The vehicle tests provided an indication of the practical significance of the identified parameters in the generation of steering drift during braking on an actual vehicle and showed clearly that the steered wheels did change their orientation during braking. It was also concluded that the most effective means 
of controlling any tendency towards steering drift during braking was to ensure minimum side-toside variation in suspension deflection and body deformation, both statically and dynamically.

This paper presents a more detailed study of wheel movement and suspension deflection under forces that are representative of those generated during actual vehicle braking and provides a comparison with actual wheel movement data measured on a test car during braking. Using a kinematic and compliance $(K \& C)$ test rig, movements of the front wheels and the suspension subframe, together with corresponding changes in suspension and steering geometry under simulated braking conditions, were measured at different levels of suspension movement. Dynamic measurements of front wheel and suspension movements were then measured on an actual test car, which provides good correlation with the $\mathrm{K} \& \mathrm{C}$ test measurements. The result is a better understanding of the causes and effects of steering drift during braking, which will assist in a better design of passenger car front suspension systems for vehicle stability during braking.

\section{STATIC MEASUREMENTS OF FRONT SUSPENSION DEFLECTIONS UNDER BRAKING FORCES}

A front wheel drive family saloon with a McPherson strut design of front suspension, of the same design as the car previously used by the authors [1], was selected for the static measurements. The design of the suspension included the lower wishbone (also known as the 'A-arm') pivoted to a subframe via rubber bushes, the subframe mounted to the vehicle body via rubber mounts and the top of the strut mounted directly to the vehicle body via rubber bushing at the suspension turrets.
The static measurements were carried out under one author's instruction by IKA (Aachen University) on their kinematic and compliance (K\&C) test rig facility. The toe-steer and camber angles, caster angle and kingpin inclination angle were measured by a standard wheel alignment test device. A threedimensional coordinate measuring device was used to measure the actual position of the wheel centre points, tyre contact patch centre, strut rotation (top), lower ball joint and the front and rear mounting point of the subframe to the body. The measurement accuracy was estimated to be $\pm 0.05 \mathrm{~mm}$ [4]. Vertical and longitudinal forces were applied at the positions of the tyre patch centres; the wheels were not included to avoid tyre deflection effects [4]. The measurements from the K\&C rig are summarized as follows.

\subsection{Steering offset}

The measured steering offset (Scrub Radius) varied from $-6.5 \mathrm{~mm}$ at the nominal operating condition (static load/deflection) to approximately $-8.5 \mathrm{~mm}$ at $25 \mathrm{~mm}$ suspension compression (jounce), as shown in Fig. 1. The right side steering offset was slightly greater than the left side by approximately $1 \mathrm{~mm}$ at $25 \mathrm{~mm}$ suspension compression.

\subsection{Tyre contact patch centre position}

Longitudinal forces of $2800 \mathrm{~N}$ (front) and $1500 \mathrm{~N}$ (rear), being representative of maximum measured vehicle deceleration $\left(9.7 \mathrm{~m} \mathrm{~s}^{2}\right.$, almost 100 per cent $g$ ), were applied to each tyre contact patch position on the $\mathrm{K} \& \mathrm{C}$ rig. The front suspension compression was increased from 0 to $25 \mathrm{~mm}$ in $5 \mathrm{~mm}$ increments. The results are summarized in Figs 2 and 3.

As the suspension compressed, the track increased, but the right wheel showed a bigger lateral deflection than the left wheel. As expected, the longitudinal

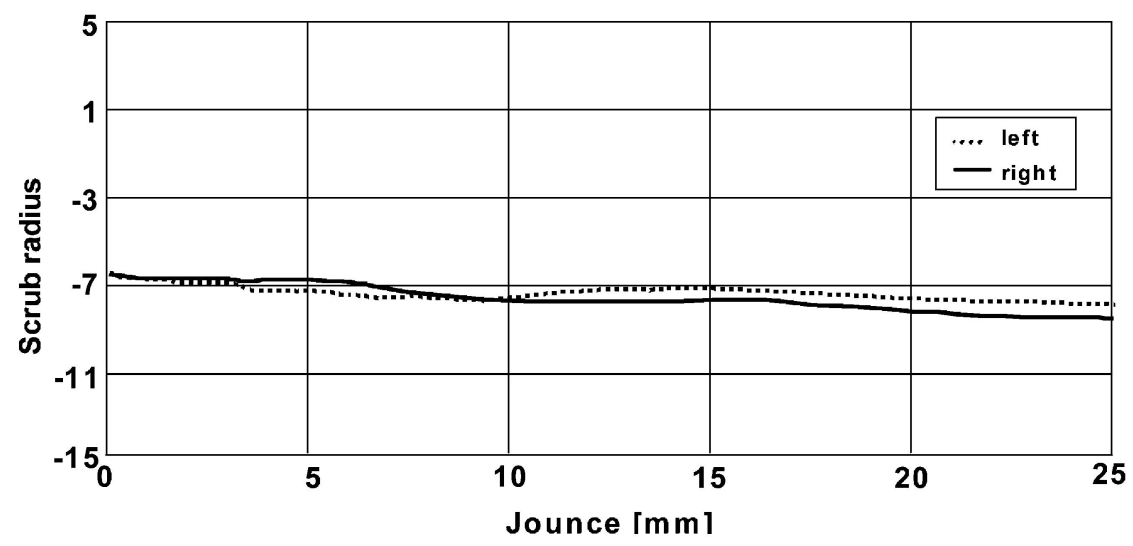

Fig. 1 Scrub radius: jounce dependence 


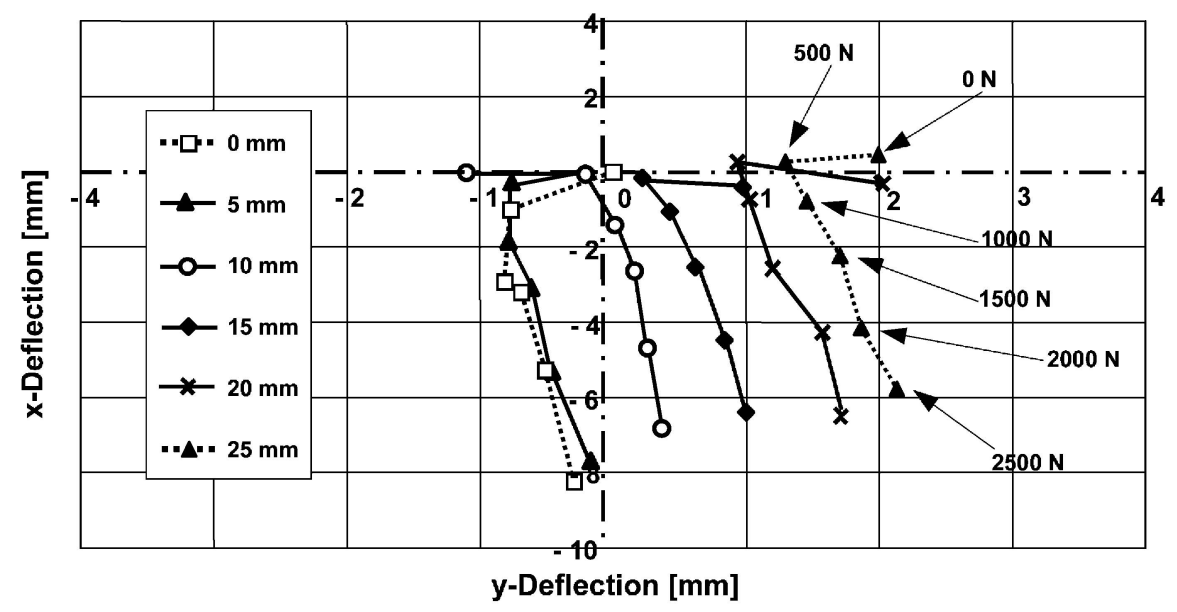

Fig. 2 Horizontal deflection of the left wheel depending on compression and brake force

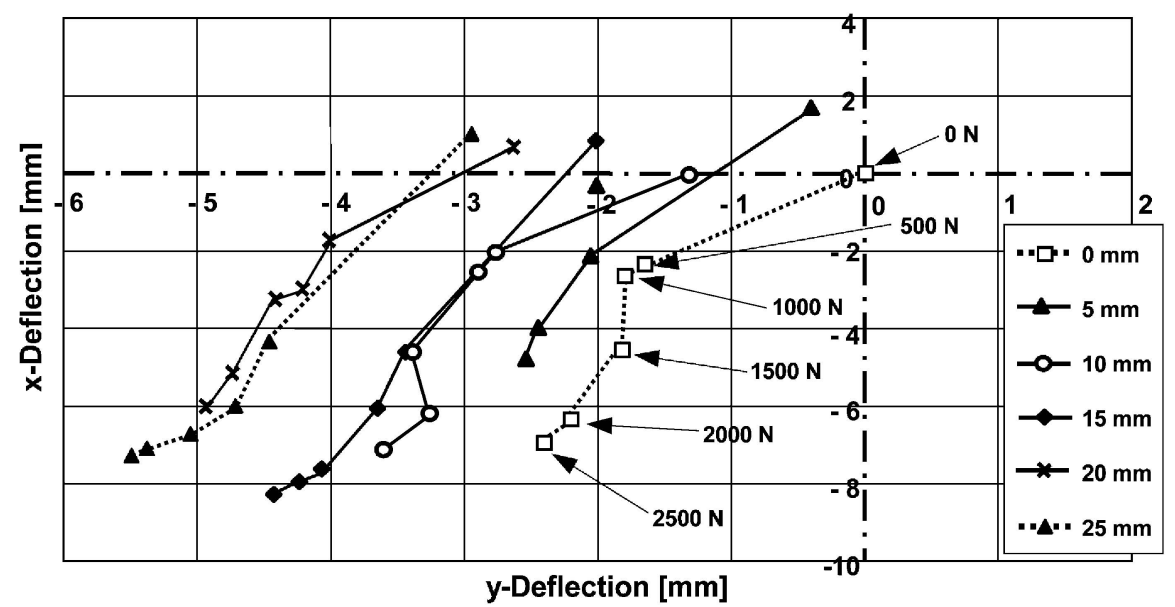

Fig. 3 Horizontal deflection of the right wheel depending on compression and brake force

brake forces moved the contact patch backwards; both wheels moved by approximately the same amount. These results confirmed that the steering offset change was different side to side, but this difference was small and insufficient to change the steering offset between positive and negative values.

\section{DYNAMIC MEASUREMENTS OF FRONT SUSPENSION DEFLECTIONS UNDER BRAKING FORCES}

The same test car was used for the dynamic measurement of wheel and suspension movements under actual driving conditions. The measurements included large movements up to $50 \mathrm{~mm}$ (e.g. the suspension vertical movement) and smaller deflections up to $5 \mathrm{~mm}$ (e.g. bush deflection). The instrumentation used was required to be tolerant of temperature, vibration and shock, and was also compact and lightweight.

A 'rope potentiometer' method was selected to measure deflections of the wheels and suspension. The principle of the rope potentiometer was that one end of an inextensible cord was attached to the point whose movement was to be measured and the other end was coiled tightly around a drum attached to a rotary potentiometer. As the cord was drawn out, the potentiometer was rotated, giving a signal output proportional to the extension of the cord. This technique was accurate, robust and convenient for use on the vehicle. Three such potentiometers were required to define precisely the movement of the point of interest in three-dimensional space and, as an example, the arrangement for measuring the wheel centre position is shown in Fig. 4. Two of 


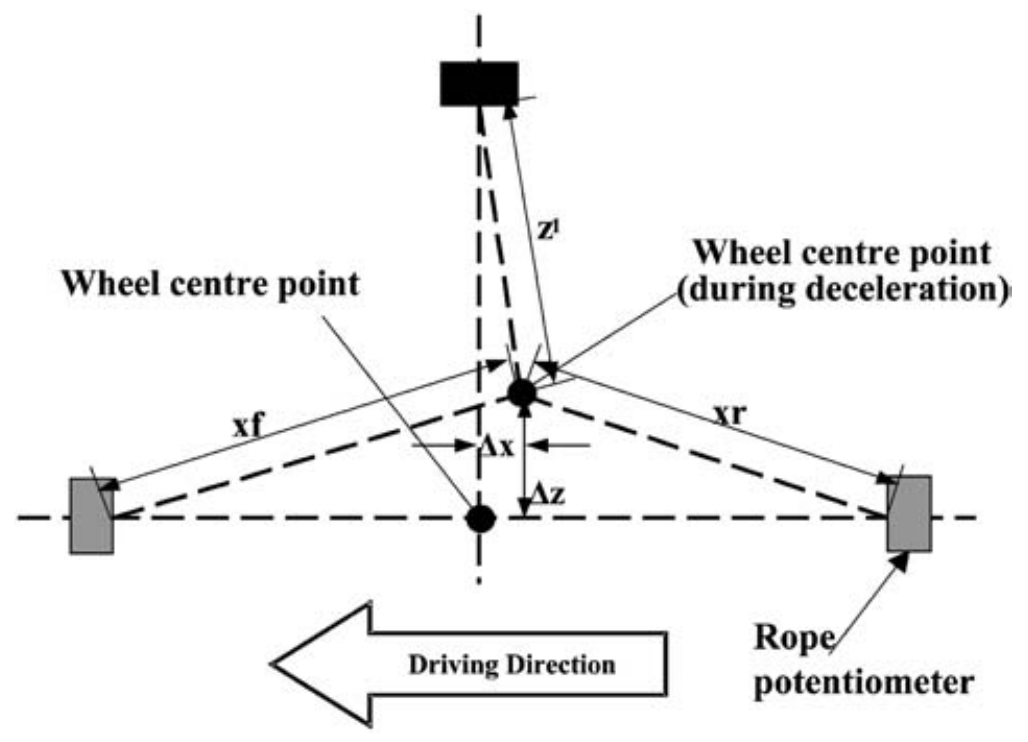

Fig. 4 Arrangement of three rope potentiometers to measure the wheel centre

the potentiometers were aligned in the $X Y$ plane, and the third was aligned in the $Z$ direction. A portable computer with an analogue-to-digital (A/D) converter and measuring acquisition software (DIA/DAGO ${ }^{\circledR}$ ) was used to log the data [4].

Movements and deflections were measured as follows:

(a) subframe relative to vehicle body: four pointstwo in $X$ and $Y$, two in $X, Y$ and $Z$ ( $X, Y$ and $Z$ represent longitudinal, transverse and vertical respectively);

(b) lower suspension arm deflection $(Z)$;

(c) wheel centre $(X, Y, Z)$;

(d) strut top $(X)$.

The measurement positions are summarized in Fig. 5. Deceleration and other parameters were also recorded as previously described by the authors $[1,4]$.

Left and right $X$ deflections of the subframe are shown in Fig. 6; the subframe moved backwards by approximately $1.55 \mathrm{~mm}$ during the test. There was no noticeable difference between 'fixed' and 'free' control (hands on or off the steering wheel).

At the mounting at the rear of the subframe, the measured vertical deflection $(Z)$ was approximately $1.2 \mathrm{~mm}$ upwards, as shown in Fig. 7. Further analysis of the subframe deflection showed that there was some small 'internal' deflection of the subframe (less than $1 \mathrm{~mm}$ ); the front left corner and the rear right corner of the subframe moved closer together. Because some suspension components are attached to the subframe and some are attached directly to the car body, these movements and deflections will differentially affect the steering geometry. The vertical deflections of the rear and front bush positions of the lower suspension 'A-arm' are shown in Figs 8 and 9, which indicate movements of approximately $2.5 \mathrm{~mm}$ upwards at the front position and approximately $4.5 \mathrm{~mm}$ at the rear position.

The wheel centre movement is summarized in Figs 10 and 11 in the vertical and longitudinal directions respectively. The peak vertical movement recorded was approximately $45 \mathrm{~mm}$ on the right wheel and $38 \mathrm{~mm}$ on the left wheel. The longitudinal measurement showed a movement of $-10 \mathrm{~mm}$ (backwards) for the right wheel, compared with $-8 \mathrm{~mm}$ for the left wheel at the start of the test, while towards the end of the test the two sides converged to a value of $9 \mathrm{~mm}$, with a definite indication of greater movement at the left wheel. The strut top position moved forwards by up to $0.75 \mathrm{~mm}$ during the test, as shown in Fig. 12.

\section{DISCUSSION OF RESULTS}

Both the static tests $(\mathrm{K} \& \mathrm{C})$ and the dynamic measurements presented here have shown how a vehicle's suspension geometry can change during braking. The measurements have enabled changes in steering and suspension design parameters to be calculated and their effects to be analysed. Of particular interest were the change of steering offset and the wheel centre position during braking, which were measured under static conditions of longitudinal braking force for different amounts of suspension compression. These measurements confirmed that not only was 


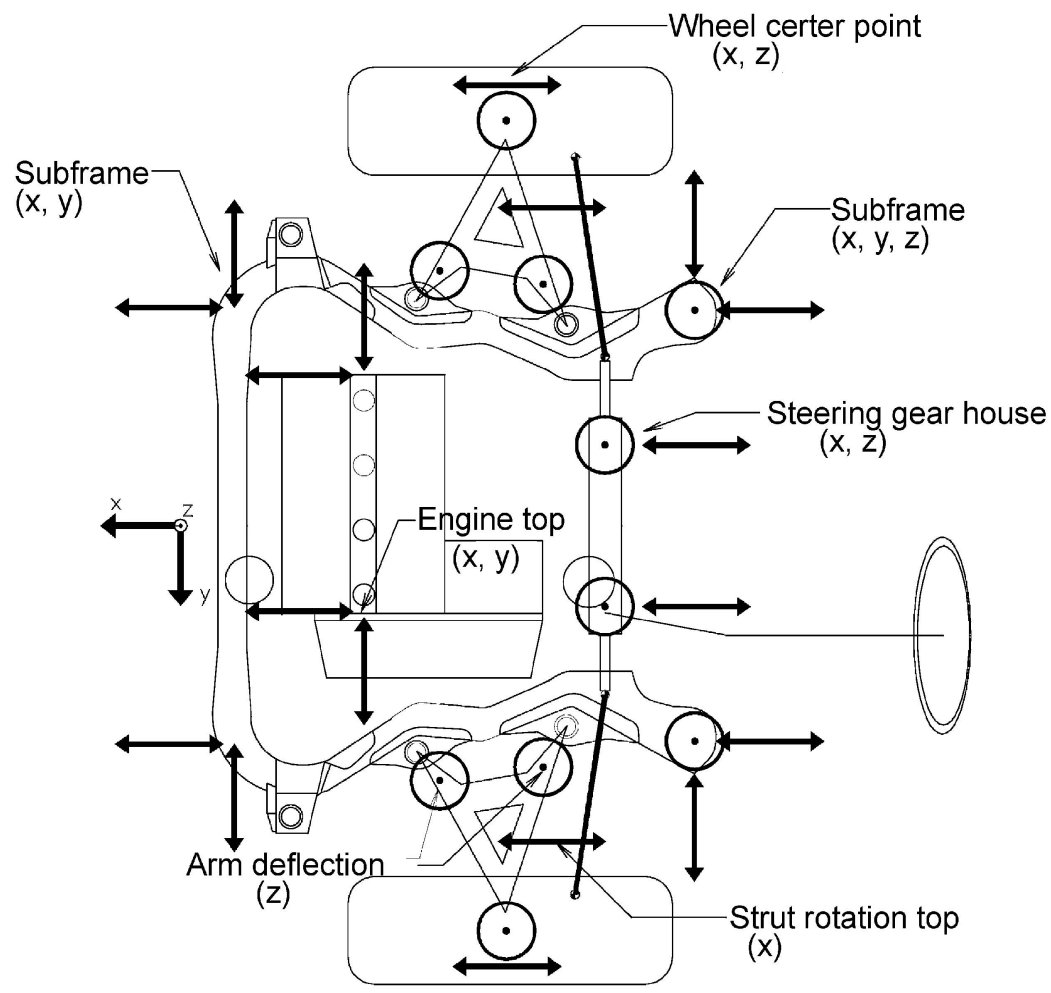

Fig. 5 Measurement positions at the subframe, A-arms, strut rotation top, engine and steering gear housing

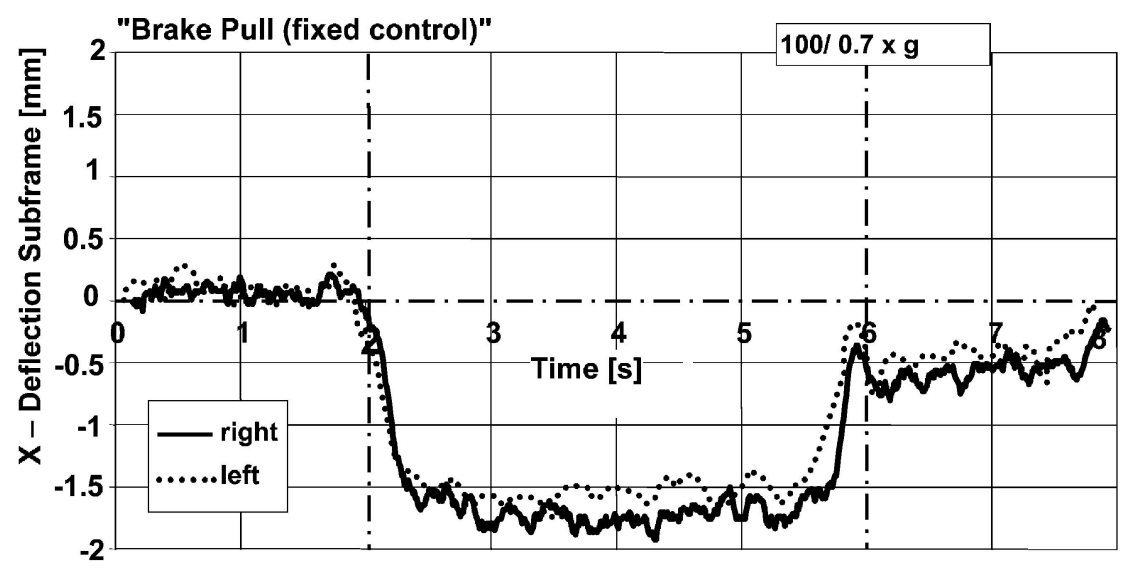

Fig. $6 X$ deflection of the subframe, fixed control

there a side-to-side difference but also that this difference depended upon suspension compression (jounce).

In the authors' previous work [1] it was reported that the suspension geometry toe-steer curve was found to have no reproducible effect, indicating that the vertical deflection of the front suspension during braking did not affect steering drift. The work presented here has identified that side-to-side variation in wheel movement during braking is influenced by suspension compression, and therefore this effect should not be ignored. Reducing suspension compliance by inserting a stiffer bush in the rear pivot of the lower suspension arm was previously found to reduce the suspension arm deflection and control the wheel orientation better during braking, and the work presented here further reinforces this finding.

The authors also found [1] that suspension compliance (as defined by the front suspension lower wishbone rear bush stiffness) and the steering offset (as defined by the wheel offset) were two significant parameters in steering drift during braking. Negative 


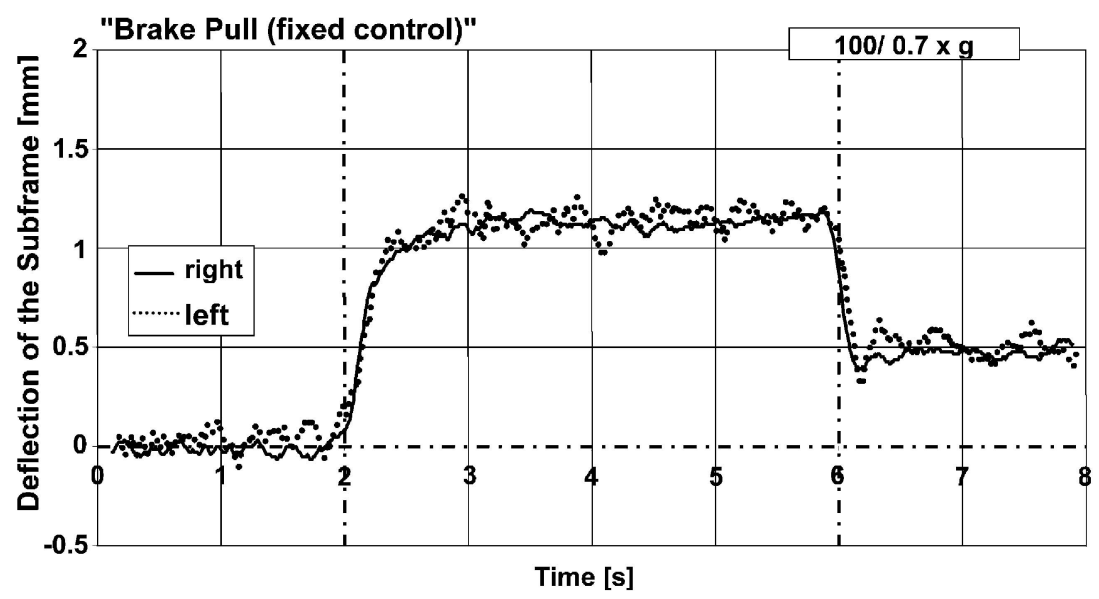

Fig. $7 \quad Z$ deflection of the subframe, fixed control

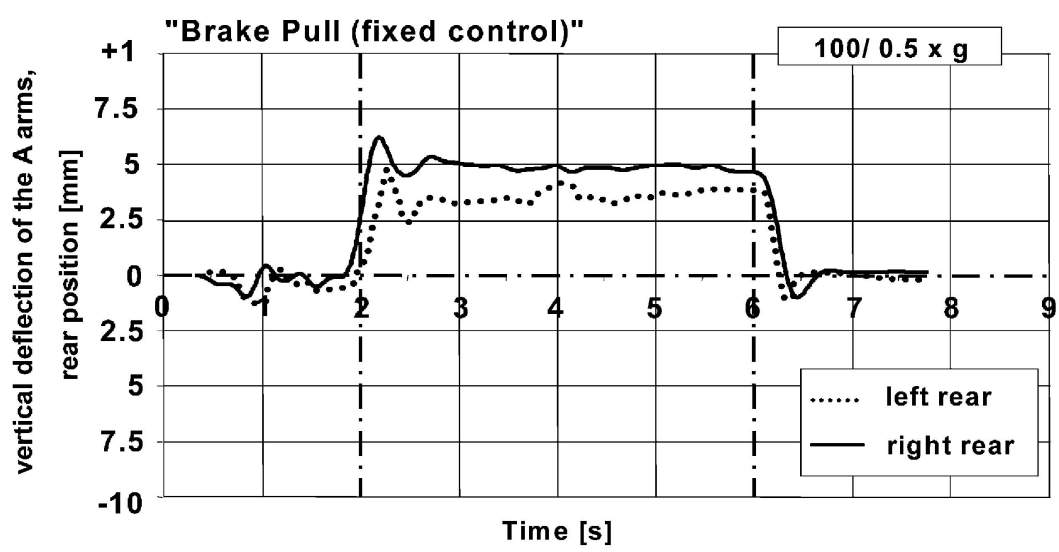

Fig. 8 Vertical deflection ' $Z$ ' of the A-arm rear position, fixed control

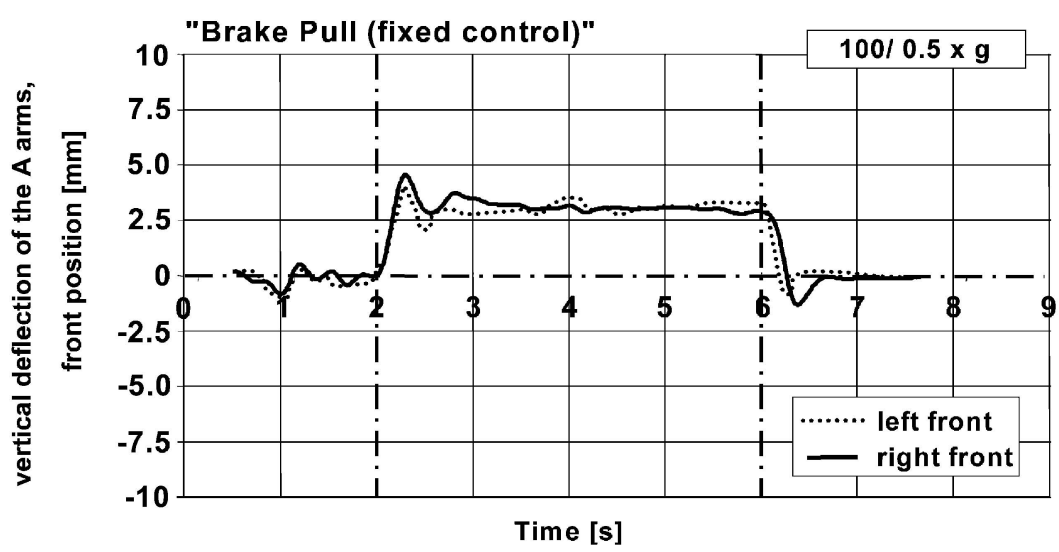

Fig. 9 Vertical deflection ' $Z$ ' at the front position at the A-arms, fixed control

offset steering was confirmed to have minimum sensitivity to side-to-side brake torque variation, and thus the variation in steering offset found here is relevant.

Under dynamic conditions the authors [1] found that the caster angle could become slightly negative. From the results presented here, the dynamic caster angle was calculated from the measured wheel centre deflection data and the three associated parameters of caster angle, caster trail (at the wheel centre) and caster offset (at the road surface) are illustrated in Fig. 13. The reaction force at the tyre contact patch generates a steering force when the caster is nonzero, the magnitude of which depends upon the caster angle and the kingpin inclination. The caster angle is normally designed to be positive to give a 


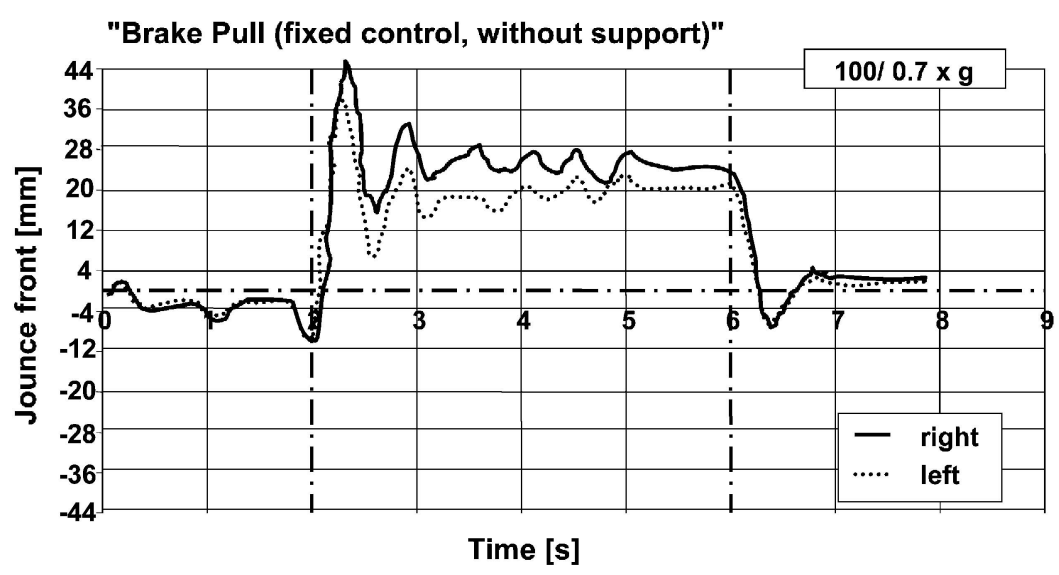

Fig. 10 Jounce at the front axle

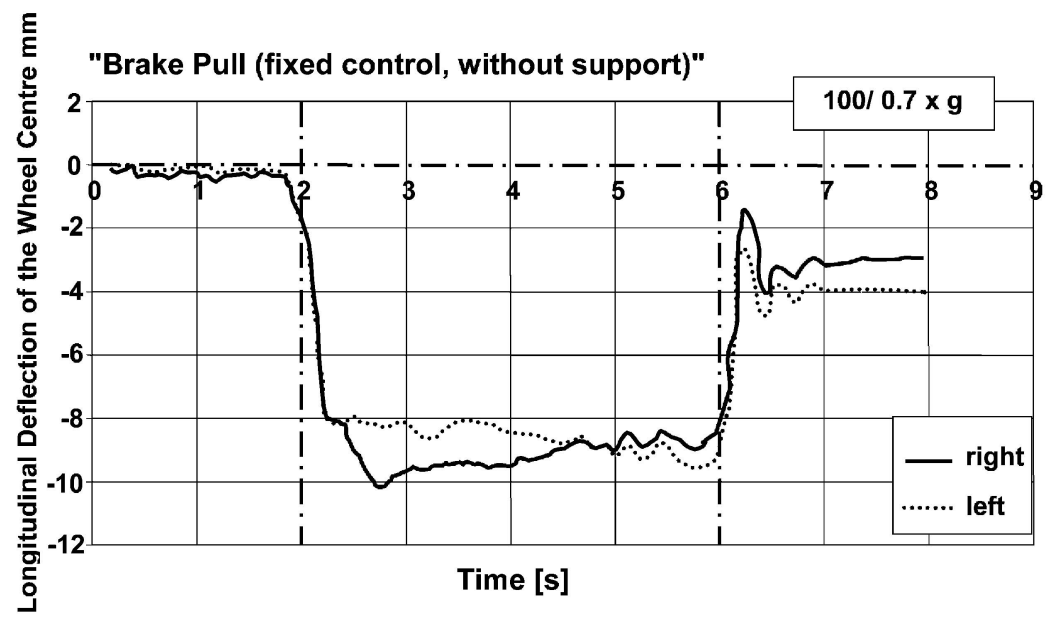

Fig. 11 Longitudinal deflection of the wheel centre points, fixed control

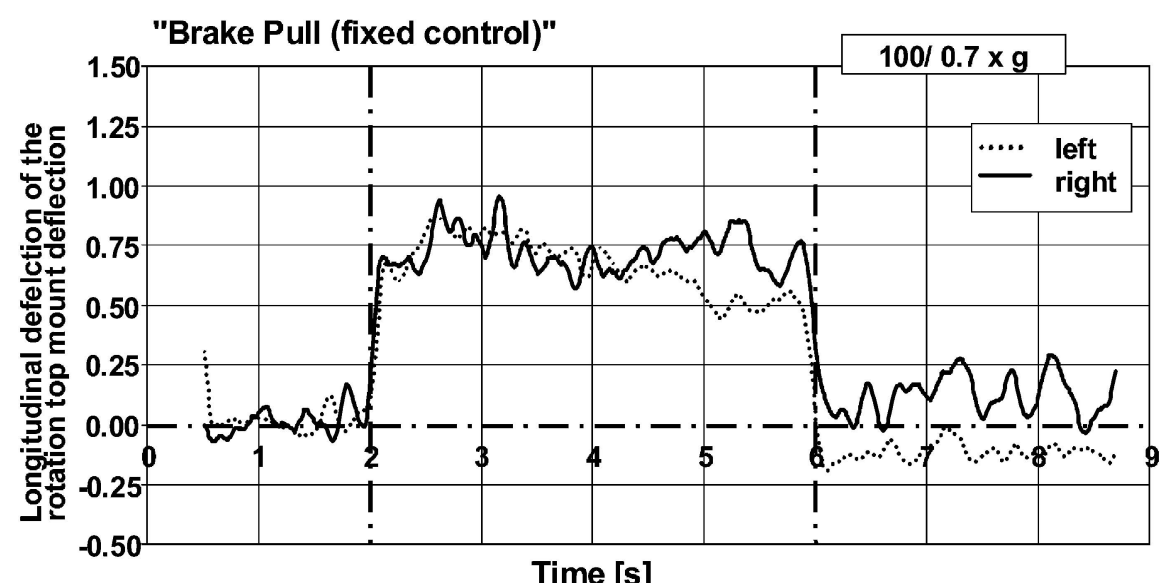

Fig. 12 Longitudinal deflection of the strut rotation top, fixed control

self-aligning torque, but if the caster angle reaches a negative value, then this torque works in the opposite way. The results from the dynamic tests indicated that the caster angle did in fact change from positive to negative; this was a compound effect that included a difference of nearly $1 \frac{1}{2}$ between the nominal and actual $\left(+3^{\circ}\right.$ to $+1.6^{\circ}$ approximately), a non-zero caster trail at the wheel centre, a vehicle pitch angle of up to $1.5^{\circ}$ and longitudinal deflection of the wheel centre relative to the strut top. The net result was that the right wheel in this case reached a negative caster angle during braking before the left 


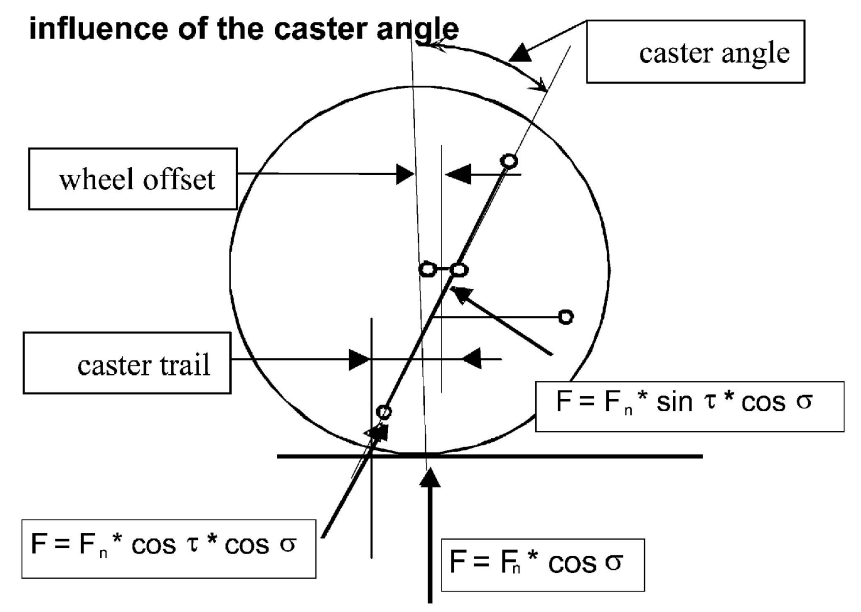

Fig. 13 Caster forces caused by the wheel load ( $\sigma=$ kingpin inclination angle, $\tau=$ caster angle)

wheel early on in the brake application. Towards the end of the brake application, both wheels had switched from positive to negative camber, with a consequential loss of self-aligning torque. The maximum values of the dynamic caster angle and caster trail are shown in Table 1.

The self-aligning torque arising from the caster is only one of several sources of self-aligning torque, which include, for example, the pneumatic trail of the tyre, so the change from positive to negative caster angle would not in itself destroy the vehicle stability. However, a reduction in self-aligning torque is likely to allow other effects of steering drift to be more clearly felt. This was confirmed in a further test when the suspension was modified to be able to adjust the caster angle. When the settings were adjusted to give the same static caster angle on each side, no effect of different caster angles was perceived (subjectively) by the driver. When the static caster angles were adjusted to be different from one side to the other, the driver noticed a greater tendency to drift to one side during braking.

\section{CONCLUSIONS}

The major cause of steering drift during braking has previously [1] been found to be side-to-side dynamic variation in the deformation and deflection of sus-

Table 1 Dynamic caster angle and caster trail

\begin{tabular}{lcll}
\hline & $\begin{array}{l}\text { Nominal } \\
\text { value }\end{array}$ & $\begin{array}{l}\text { Maximum } \\
\text { dynamic } \\
\text { value: left }\end{array}$ & $\begin{array}{l}\text { Maximum } \\
\text { dynamic } \\
\text { value: right }\end{array}$ \\
\hline Caster angle (deg) & 3.00 & -0.45 & -0.80 \\
Caster trail (mm) & 14.64 & -1.5 & -3.8 \\
\hline
\end{tabular}

pension and steering components, and not side-toside variation in brake performance. The research results presented here confirm that finding and give more insight into this complicated phenomenon, emphasizing that steering drift during braking is an issue at the system level and not merely at the component level. The phenomenon cannot be addressed in terms of any single design characteristic of the vehicle suspension or brake system design. It can therefore be concluded that a fully integrated dynamic model of the vehicle chassis would be a most valuable tool in chassis system design for stability.

The accuracy of the measurements made depended upon the transducer accuracy and then the computational error in the derivation of parameter values. The accuracy was estimated to be no worse than $0.5-1$ per cent. Therefore it can be concluded that any experimental error is unlikely to affect the results and thus make their interpretation invalid.

The measurements presented here agree with previous data [1] relating to the movement of the front wheels and consequent toe-steer effects. The conclusion that control of compliance at each side of the vehicle is critically important in minimizing steering drift during braking is thus reinforced. In addition, however, it can be concluded that it is equally important to ensure that the compliance and resulting deflections at both sides of the vehicle are as near the same as possible. Minimizing the compliance overall is helpful in achieving this aim, but this represents a compromise in terms of ride harshness and shock transmission.

An important finding was that the combination of the rearwards wheel movement with vehicle pitch change during braking was sufficient under the conditions of test to change the caster angle in this design of suspension from positive to negative. It is unlikely that this change in itself would be noticed by the driver, but the consequent reduction in selfaligning torque from the caster is likely to allow other effects of steering drift to be more clearly felt. It may therefore be concluded that analysing and understanding changes in the caster angle during braking at the vehicle design stage is good practice.

Compressing the suspension increased the track width of the test vehicle and altered the steering offset. The change in steering offset was found to be small in absolute terms (a few $\mathrm{mm}$ ) and could be different from side to side. However, it is also important to note that every change in the steering offset on each side will create an imbalance from side to side because of the difference in the steering 
arm forces, and therefore it can be concluded that the steering offset (scrub radius) is another design parameter of importance in designing for 'drift-free' braking.

Experimental measurements such as the static $\mathrm{K} \& \mathrm{C}$ tests are a useful way of identifying and confirming braking-induced deflection characteristics of a vehicle suspension. However, an integrated vehicle dynamics model (as mentioned above) is seen as a more versatile way forward.

\section{ACKNOWLEDGEMENTS}

This paper presents research carried out as part of an MPhil study with the University of Bradford. The authors are grateful to all who contributed to the research, including staff in the Ford Motor Company,
IKA (Aachen) and supplier companies. Thanks also go to the Directors of the Ford Motor Company for permission to publish this paper.

\section{REFERENCES}

1 Klaps, J. and Day, A. J. Steering drift and wheel movement during braking: parameter sensitivity studies. Proc. Instn Mech. Engrs, Part D: J. Automobile Engineering, 2003, 217(D12), 1107-1115.

2 Holdman, P., Kohn, P., Moller, B. and Willems, R. Suspension kinematics and compliance-measuring and simulation. SAE paper 980897, 1998.

3 Momoiyama, F. and Miyazaki, K. Compliance steer and road holding of rigid rear axle for enhancing the running straightness of large sized vehicles. SAE paper 933009, 1993.

4 Klaps, J. Investigation of the effects of the longitudinal stiffness of the engine subframe and suspension system during straight-line braking in passenger cars. MPhil thesis, University of Bradford, 1999. 